\title{
LA PRESENCIA INDÍGENA EN EL ENCLAVE SALITRERO DE TARAPACÁ: UNA REFLEXIÓN EN TORNO A LA FIESTA DE LA TIRANA
}

\author{
THE INDIGENOUS PRESENCE IN THE NITRATE ENCLAVE OF TARAPACÁ: \\ A REFLECTION ON THE RELIGIOUS CELEBRATION OF LA TIRANA
}

\author{
Sergio González Miranda ${ }^{1}$
}

\begin{abstract}
Este es un trabajo que analiza la presencia indígena en las salitreras de Tarapacá y conjetura que la fiesta de La Tirana fue refundada durante el período del salitre. Escasos son los estudios sobre la relación entre el mundo andino y el mundo del salitre, cuya mutua influencia ha quedado oculta detrás de la sombra de la organización y movimiento obrero, por un lado, y de la comunidad aymara, por otro. Sin embargo, festividades populares y rituales como La Tirana ponen de manifiesto la influencia indígena en el enclave salitrero y, a su vez, el impacto de éste en la cultura andina.
\end{abstract}

Palabras claves: salitre, cosmovisión andina, ritual, movimiento obrero, comunidad indígena.

This work analyzes the indigenous presence in the nitrate places of Tarapaca and suggests that the religious feast of La Tirana was re-founded during the period of the nitrate. There are scarce studies about the relation between the Andean world and the nitrate world, whose mutual influence has been hidden in the shadow of the labor movement and organization, on one side, and the Aymara community, on the other. Nevertheless, popular rituals and festivities, such as La Tirana, evince the indigenous influence in the nitrate enclave and, also the impact of this in the Andean culture.

Key words: Nitrate, Andean cosmovision, ritual, labor movement, indigenous or native community.

La expresión de fe que todos los años se vive en pleno Desierto del Tamarugal, en el pueblo de La Tirana, cuando se le rinde culto a la Virgen del Carmen, siempre llama la atención a nivel del país, tanto por la gran cantidad de fieles y visitantes que llegan a ese poblado a mediados de julio, como por el contrapunto que esa fiesta representa respecto de la vida urbana y moderna que supuestamente caracteriza a Chile.

Importantes trabajos han intentado explicar el origen y desarrollo de esta fiesta religiosa (van Kessel 1987; Núñez 1988); todos han abordado distintos ángulos del fenómeno, con hipótesis plausibles e interesantes trabajos de investigación. Sin embargo, consideramos que todavía es posible darle una vuelta más a la reflexión sobre algunos aspectos particularmente relevantes: uno de ellos es el desierto y otro es la industria del nitrato.

Conjeturamos, por una parte, que el desierto no es meramente el contexto donde se manifiesta esta fiesta religiosa, sino que tiene una influencia clave en su expresión y, por otra, que "La Tirana" es un fenómeno sociocultural salitrero, al menos hasta 1950. Sin desconocer que esta festividad pudo tener su origen en el ciclo de la plata, como lo señala Núñez (1988), planteamos que fue simbólicamente re-fundada en el siglo diecinueve durante el ciclo del salitre.

Los desiertos siempre han sido vinculados al surgimiento de la religión. Más allá de la experiencia mística que pueda generar un ambiente como ese y sin caer en un determinismo geográfico, pareciera que, como lo señala Le Goff, desempeñó "un papel importante en las grandes religiones euroasiáticas: el judaísmo, el islamismo, el cristianismo" (2002:25).

El Desierto de Atacama es uno de los más secos del planeta y, por lo mismo, podría considerarse que es un ambiente propicio para la conducta mística. Sin embargo, ese aspecto ha quedado, al

\footnotetext{
1 Instituto de Estudios Internacionales, Centro de Investigaciones del Hombre en el Desierto, Universidad Arturo Prat, Iquique, Chile.sgonzale@unap.cl
} 
menos en el período del ciclo del salitre, oculto para la historiografía especializada.

La elección del Desierto de Atacama con propósito de habitarlo no está relacionada con el aislamiento místico. El habitante del desierto en el ciclo del salitre, conocido como "pampino", llegó a esos parajes producto de un gran fenómeno económico de explotación de la naturaleza. Hombres y mujeres llegaban en busca de trabajo a un desierto en cierto modo "institucional"; el enganchado no pretendía "alejarse de la civilización", sino, al contrario, la buscaba y la encontraba en los campamentos salitreros, los que fueron notoriamente urbanos. La pampa salitrera era la modernidad si se le compara con las zonas rurales, como las chilenas, bolivianas o peruanas. Había en los campamentos escuelas, bibliotecas, filarmónicas, teatros, retretas, etc.; en los pueblos se encontraban casi todos los servicios públicos, incluyendo a la policía y la iglesia, además de las casas de juego y el comercio. También estaban, como la máxima expresión de la modernidad de esa época, la tecnología, la planta de lixiviación del nitrato, la industria salitrera que era el motor de la economía nacional. Incluso, respecto de la tecnología como de la cultura, a veces llegaban directamente desde Europa sin pasar por las grandes ciudades como Santiago o Valparaíso, pues los barcos traían el cabotaje directamente a los puertos salitreros.

Quizás esta sea la razón que explique la mirada historiográfica que rescata a un movimiento social salitrero moderno, incluso ilustrado, por sobre un movimiento social salitrero vinculado a expresiones místicas y religiosas. El obrero ha estado siempre como protagonista, junto con los grandes empresarios y administradores, de la historia del salitre.

Si bien la elección del desierto no fue mística, las características propias de este tipo de naturaleza, que estremeció a los sujetos de un modo comparable sólo con un gran océano, no podía sino tener un impacto tanto en la mentalidad como en las formas de vida en los campamentos salitreros. También por la presencia de población de origen campesino e indígena, el componente místico llegó a las salitreras junto con prácticas culturales propias, como fueron los casos de las poblaciones de habla aymara o quechua (González 1996).

No nos habíamos preguntado si el Desierto de Atacama en general y el del Tamarugal, en particular, generaron o no una ideología, una religión, un ethos, una identidad o un misticismo. No dudamos en reconocer que hubo una ideología obrera que surgió desde el norte salitrero (Reyes Navarro 1973; Fernández Canque 1988; Pinto Vallejos 1995) e influyó no solamente en el resto del territorio nacional, sino también en países fronterizos como Bolivia (Rodríguez Ostria 1991) y Perú (Pereda 1982), pero vemos su germen en el pensamiento ilustrado europeo, sea este socialista, anarquista, positivista, mutualista, etc., nunca relacionado con el desierto mismo. Incluso la propia fiesta de La Tirana no es consistente con esta ideología obrera ilustrada y, por lo mismo, se omite su importancia en el movimiento social salitrero (Figura 1).

No es posible desconocer la presencia indígena en el ciclo del salitre, tanto en Antofagasta como en Tarapacá, incluso una leyenda les relaciona con el origen del salitre. Según una leyen$\mathrm{da}$, dos indígenas descubrieron casualmente el caliche producto del asombro de ver cómo la tierra comenzaba a arder debido a una fogata que habían encendido. Roberto Hernández nos cuenta que corrieron despavoridos a contarle al cura de Camiña lo sucedido:

El cura volvió con los indígenas, llevando una provisión de agua bendita; y después de recorrer el lugar, hizo en el curato algunos análisis de las tierras que habían recogido y encontró que las muestras tenían Nitrato de Potasio, que se empleaba para la fabricación de la pólvora. El resto de las muestras fue depositado en el patio de la casa del curato; y ¡cuál no sería la sorpresa del Cura de Camiña, cuando notó, más tarde, que las plantas allí existentes comenzaban a desarrollarse de un modo extraordinario! (Hernández 1930:4).

El desierto, durante el ciclo del salitre, fue habitado, nombrado y simbolizado en base a una nueva hipóstasis de la realidad. El fenómeno del nitrato inaugura no sólo una nueva sociedad en el desierto, distinta al ciclo de la plata, sino un nuevo desierto y, por añadidura, una nueva Virgen y nuevas cofradías. Lautaro Núñez, en su notable libro sobre La Tirana, nos narra el desarrollo del mito y sus acontecimientos más importantes, como la llegada en el período del salitre de una nueva Virgen (la de piedra) y de nuevos bailes religiosos (Núñez 1988:45). 


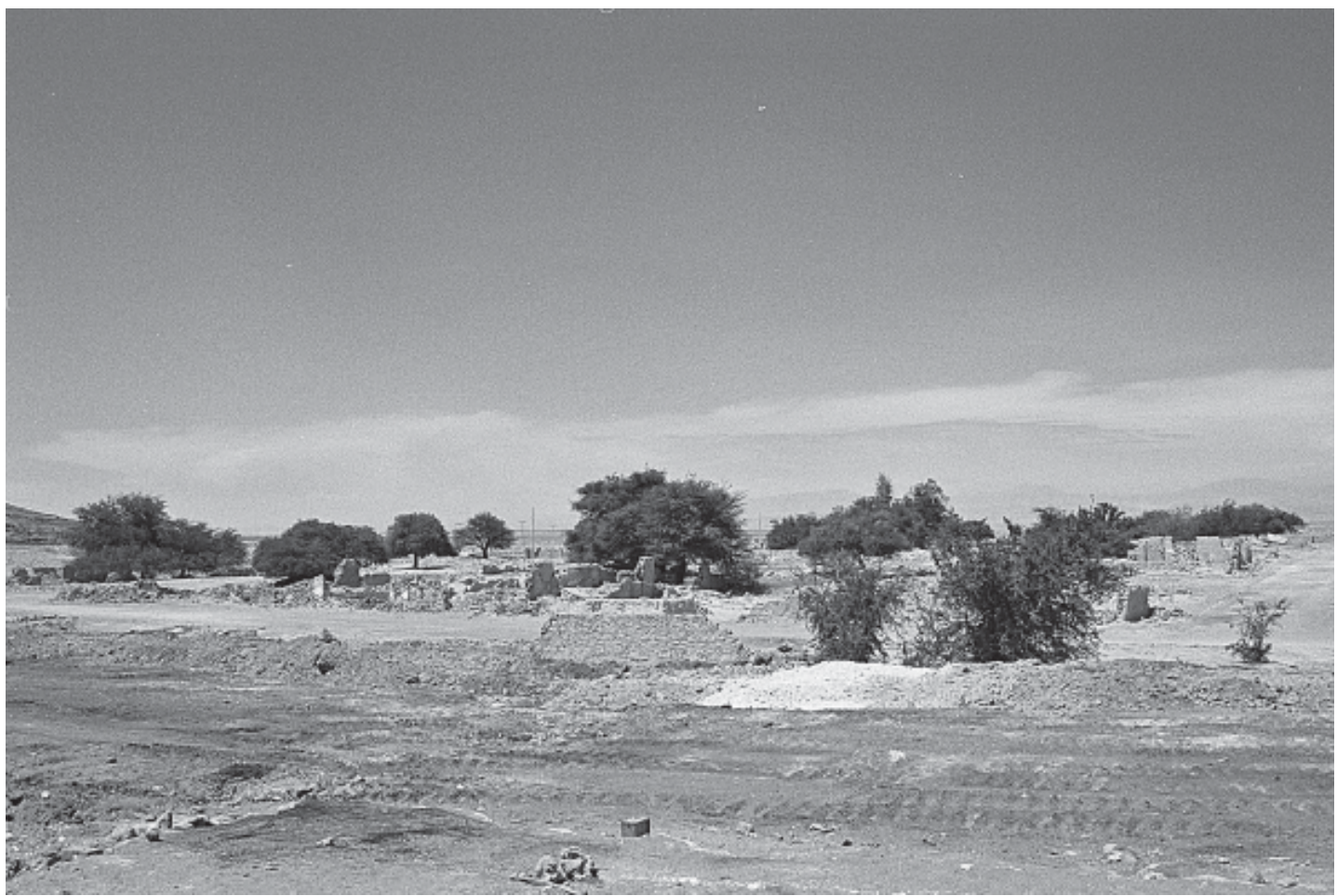

Figura 1. Ruinas del pueblo de Zapiga, interior de Pisagua.

Ruins of the nitrate Zapiga village, Pisagua hinterland.

El desierto salitrero fue un lugar de desarraigo, porque la sociedad que allí surgió fue compuesta en gran parte por enganchados o aventureros. La profundidad del linaje de las familias del desierto salitrero era breve, no se alejaba más allá de 1810, cuando se experimentaron las primeras "ollas del indio" que lixiviaron rústicamente el caliche. La importancia de la madre acogedora para el desarraigado siempre fue importante. La organización mutualista le ofreció al obrero un espacio de protección, solidaridad y sociabilidad, después vendría la mancomunal, la filarmónica, el partido político, el teatro, el sindicato; también el campamento fue un microcosmos donde se tejieron las redes sociales que permitieron darle seguridad al pampino. Empero, fue insuficiente, la cofradía tuvo un papel fundamental en esa búsqueda de refugio, protección y salud para el espíritu.

En el desierto salitrero "la palabra" recorrió los campamentos con el propósito de educar o redimir "al pueblo", ya sea en los periódicos obreros o en el discurso de los dirigentes. Tampoco fue suficiente, el trabajador de la pampa salitrera ne- cesitó también del canto y del baile religiosos para redimirse. No había contradicción, en el mundo personal del pampino, entre estos distintos aspectos de su vida: el alma se educaba en el teatro y en la filarmónica, la conciencia en el partido político, el cuerpo en La Tirana ${ }^{1}$.

Es difícil imaginar a un desierto que no ejerza cierta fuerza mística en hombres y mujeres. De igual modo, siempre ha sido entendido como un lugar de pruebas, donde el "empampado" es la imagen del perdedor, aquel que fue devorado por las fuerzas de la naturaleza, al no saber descifrar las claves del desierto. Por el contrario, quien conoce esas claves ve en el desierto un refugio, como los peregrinos que lo cruzaban para ir a adorar a la Virgen del Carmen. Ella ha sido una deidad totalizadora, su espacio fue todo el desierto salitrero, porque era reconocida en todo el territorio comprendido entre Pisagua y Taltal; en cambio, otros santos tuvieron influencia en algún espacio más local, como el caso de San Lorenzo de Tarapacá, más vinculado a los cantones del sector norte de la provincia, incluyendo los puertos de Pisagua e Iquique (Figuras 2 y 3 ). 


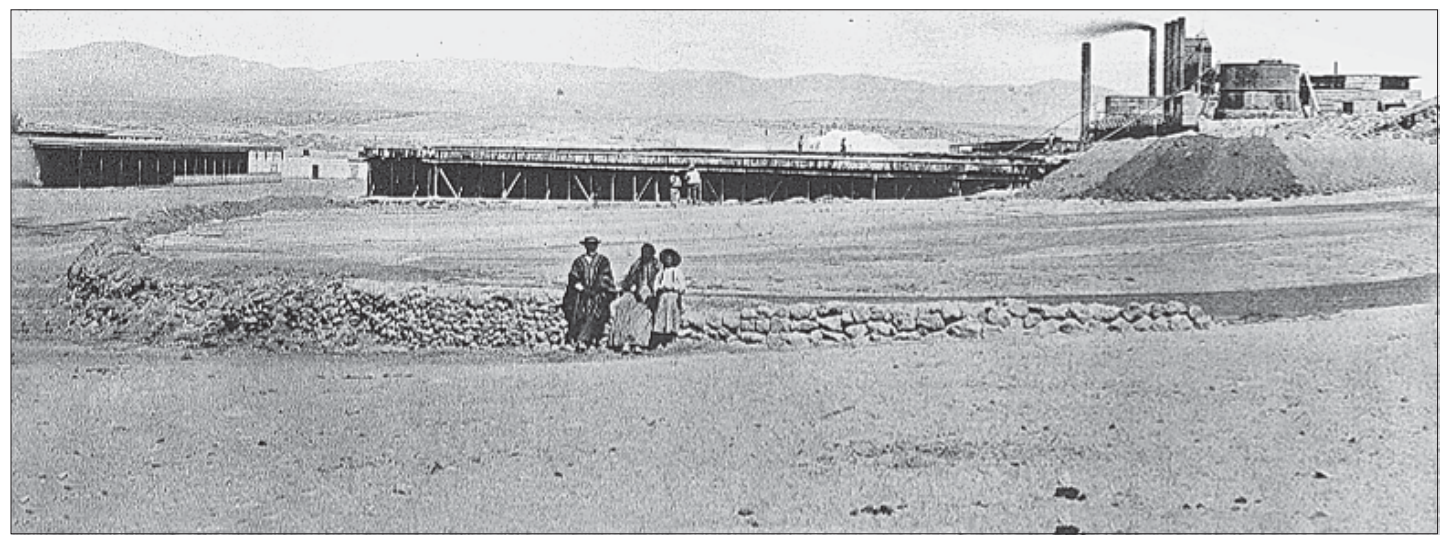

Figura 2. Familia andina en oficina salitrera del cantón Huara, Tarapacá.

Andean family in the nitrate office of the Huara canton, Tarapacá.

Por heredad del ciclo de la plata en el bosque de tamarugos aledaño al pueblo de La Tirana los pampinos encontraban allí su refugio y devoción. La Tirana, como pueblo y como bosque, expresó el encuentro con lo humano, pero en su manifestación mística y no secular. Cuando los pampinos demandaban al Estado caminaban hacia el "puerto grande" (Iquique); pero cuando demandaban a la Virgen, caminaban al bosque de La Tirana. Las peticiones colectivas fueron generadas y movilizadas a través de la mutual o el partido obrero, las peticiones personales ("mandas") fueron por medio de las cofradías religiosas o individualmente.

La ruta a La Tirana era una guía hacia la tierra (pachamama). Caminarla era una forma de tributo a la Virgen, un sacrificio de redención. La ruta al puerto grande (Iquique) era una caminata a la modernidad $^{2}$ y hacer a pie ese largo camino era un acto de desafío, un sacrificio pero de rebeldía.

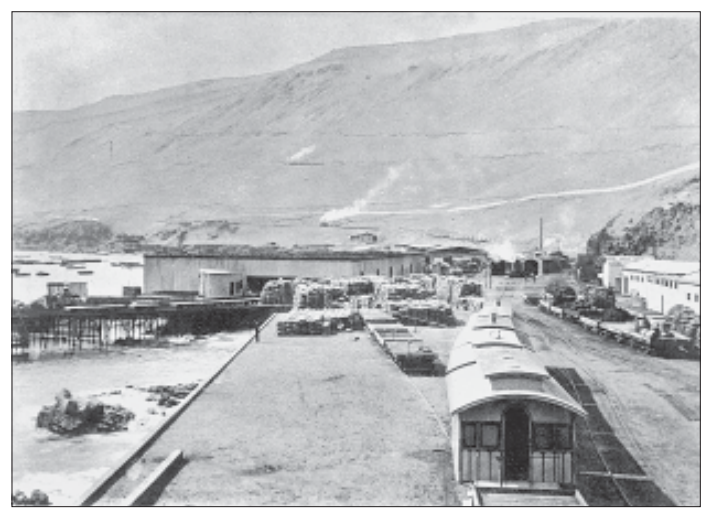

Figura 3. Puerto de Pisagua.

Pisagua port.

\section{EI Salitre}

Según el censo de 1878, que marca el inicio de la expansión del ciclo del salitre, había (se emplean categorías censales de la época) en Tarapacá 16.686 indios de un total de 38.225 personas, es decir, un $43,7 \%$. Se consideraban blancos 13.418 , un $35,1 \%$. Posteriormente los censos chilenos no considerarán la variable étnica, sino solamente las categorías por nacionalidades. Siendo las principales la chilena, peruana y boliviana. Según Gundermann (1998:176):

las décadas siguientes a la guerra precipitan ciertas modificaciones en el sistema de identidades colectivas (...) Ello se explica en parte por la acción del Estado chileno y en parte por la plena formación de una economía de enclave con la capacidad de articular a través del mercado amplias regiones adyacentes.

De lo que no puede haber dudas, es que el mundo del salitre fue esencialmente mestizo, pero esa mixtura pocas veces ha emergido en toda su expresión, debido a la influencia de la modernidad que arribaba a las playas del espacio salitrero con el cabotaje, junto a hombres y mujeres venidos desde los más variados puntos del planeta. Por su lado, el pensamiento campesino llegaba con el arrieraje, desde los más variados puntos del territorio andino. La yuxtaposición de estos dos tipos de conocimientos terminó con el pensamiento obrero ilustrado dominante en lo público, mientras el pensamiento campesino permaneció en lo privado, en los campamentos y en las faenas mineras. Empero, hubo momentos de expresión 
pública del pensamiento campesino e indígena, llenos de colorido y simbologías, fueron los casos de festividades como en el carnaval, la cruz de mayo y La Tirana.

Veamos un contrapunto entre el pensamiento "moderno" de un "obrero ilustrado" que emplea a la Virgen María para criticar irónicamente a candidatos al gobierno, respecto del pensamiento de una cofradía religiosa:

EL PUEBLO, mayo 26, 1906.

\section{VIRGEN MARÍA \\ (Letrillas cómicas)}

¡Cuántas infamias en un solo día, miramos lelos Virgen María!

Al acercarse las elecciones estamos como laucha o ratones, sufriendo latas y sensaciones, pues nos persiguen gatos bribones; para llevarnos a la elección, los radicales por Pedro Montt; y los de la Iglesia, rosario en mano, por el que suelen llamar Lazcano. $Y$ recompensas mil nos prometen, pero cuando ellos luego completen todas sus tramas, sus elecciones sueltan al punto contribuciones, ruines gabelas, ruines impuestos, que son tan ruines como son éstos. $Y$ cual dijo cierto tunante:

"eso es jeringa sobre el purgante". O como ha dicho cierto tronado: "tras de los cuernos ser apaleado" ¡Así la vida se irá pasando, pillos y lesos, siempre mirando! (...) ¡Cuántas infamias en un solo día, miramos lelos Virgen María!

El Microbio.

Esta mirada política de la Virgen tiene escasa relación con la de los promeseros a la Virgen de La Tirana. Veamos un fragmento de la "Primera entrada" del Baile Osada del Salitre, de la oficina salitrera Pedro de Valdivia, de fecha desconocida (van Kessel s/a Tomo II:215):

Que se abran las calles del pueblo de La Tirana que ya vamos llegando al templo consagrado.
La osada sólo sabe cumplir con sus promesas bailar con devoción
y cantar con mucho amor.
La osada del Salitre
te viene a saludar en tu día, madre santa, $y$ te viene a cantar.

\section{El Indígena y el Enclave Salitrero}

Durante todo el ciclo del salitre, los distintos grupos que llegaron a la pampa debieron identificarse como proletarios o capitalistas, obreros o patrones. El discurso de la época es claro a este respecto, incluso para adquirir la membresía en las principales organizaciones obreras de la época pasaba por pertenecer a la clase proletaria (v. gr. Mancomunales). Sin estar explícito en los estatutos, en las asociaciones de salitreros se daba la contraparte respectiva. Esta diferenciación de clase tuvo incluso una expresión espacial al interior de los propios campamentos salitreros. De tal modo, el campesino de habla indígena, fuera de la propia región o llegado de otras aledañas de países vecinos, debió introducirse a esa nueva nomenclatura de identidad social: ser proletarios u obreros. No pocos ya tenían alguna socialización en las minas bolivianas, pero muchos llegaron directamente desde sus comunidades campesinas.

Este paradigma, centrado en la clase social y sustentada en la división del trabajo, propio de un enclave industrial, estableció límites estrictos respecto al protagonismo en la construcción de la sociedad pampina y, en especial, con relación a la organización y a los movimientos sociales. Dichos límites ocultaron a ciertos grupos participantes del proceso social de las salitreras, como fue el caso de la población indígena. Esta, no siendo pequeña cuantitativa ni cualitativamente, se asimiló al paradigma dominante. Incluso, en aquellas oportunidades, cuando la categoría étnica entró en contradicción con la obrera fue duramente reprimida: como la crítica obrera a los indígenas rompe-huelgas o "crumiros", que en algunos casos llevó a actos violentos como ponerle polleras por la fuerza, con el propósito de humillarlos para que "tomaran conciencia". Otro ejemplo fue la oposición obrera a los enganches bolivianos ${ }^{3}$. De hecho, en los campamentos salitreros, dentro de la población obrera, 
también hubo una diferenciación social y física por procedencia étnica o nacionalidad de los sujetos.

La Comisión parlamentaria que visitó la zona salitrera en 1913 pudo identificar al indígena boliviano al interior de los campamentos salitreros, con el prejuicio de rigor, en las salitreras de los cantones norte de Tarapacá, señalando lo siguiente:

La zona norte de Tarapacá está poblada por trabajadores bolivianos, que forman la mayoría del elemento obrero en esa región, y tiene también los peores campamentos, los más viejos, estrechos y desaseados. Se ve en ellos que las basuras y los desperdicios se recogen de tarde en tarde y sólo para amontonarse a corta distancia de las habitaciones. Los chiqueros y porquerizas están en común con éstas y el mal olor es casi siempre insoportable para quienes no sean sus habituales pobladores.

La Comisión fue informada, y puede decir que comprobó esta información, de que es casi imposible obtener una mejora en el aseo de esos campamentos. El trabajador boliviano es casi siempre un indígena en estado de semi-barbarie: vive en común con los animales, duerme con ellos, y cuando en algunas oficinas se ha hecho porquerizas y corrales especiales, algo distantes de los campamentos, para evitar el desaseo, ese trabajador burla la vigilancia de los guardianes nocturnos del campamento y va al corral y substrae sus cabros y cerdos para hacerlos dormir en su propia habitación. ¿Obedece esto sólo al deseo de evitar los robos? (Comisión Parlamentaria 1913:225).

El punto de vista del Estado boliviano de esta situación es completamente diferente, veamos un editorial de El Diario de Oruro de 1919:

12 de febrero, s/p, Notas Editoriales. Nacionalización del trabajo

La repatriación de los obreros bolivianos que regresaron al hogar abandonado desde hace muchos años; después de haber emigrado a playas extranjeras en pos de trabajo para procurarse una mísera existencia, a fuerza de ruda labor material, da margen para pensar en el mejoramiento de sus condiciones dentro de la patria, a fin de retenerle como elemento de progreso, cuyos servicios serían utilizados en las industrias mineras, fabriles o agropecuarias.

La falta de una legislación completa acerca de la nacionalización del trabajo, motiva que hombres jóvenes y vigorosos abandonen el terruño para ir en busca de mejor existencia a otras regiones extrañas para el obrero, en las que tiene que luchar durante muchos años, a fin de avenirse a un medio ambiente en que no ha vivido. Luego forma hogar y si se acuerda de la patria, es sólo para hacer reminiscencia de tiempos felices de la infancia.

Las empresas mineras gerentadas por extranjeros o nacionales, deberían ser obligadas a admitir en sus labores a obreros bolivianos. Los trabajos de agricultura y de cuanta industria existiera en el país deberían tener la misma obligación, a fin de evitar la emigración de miles de individuos que se ven precisados de dejar el país y la familia, en pos de mejor suerte para exponerse a los azares y a las vicisitudes de la vida y en el momento menos pensado ser expulsados de grado o por fuerza, según el estado de las relaciones de amistad en que se encuentren naciones vecinas, como viene ocurriendo ahora mismo con los obreros peruanos y aún con los bolivianos, que por causa de la paralización de trabajos en las salitreras de Antofagasta y Tarapacá se ven obligados a regresar al país donde para empezar tienen que encontrar trabajo y donde los salarios seguramente han de ser reducidos; y, con el pensamiento fijo de retornar a las playas marinas, en cuanto los escollos hayan sido quitados del camino por la acción diplomática.

Si el obrero nacional estuviera garantizado dentro de su mismo país, indudablemente que preferiría no moverse de él, trabajando con ventaja para su situación económica y para el progreso material de la nación.

En cambio sabemos que las empresas mineras más poderosas de Bolivia, dan acceso a trabajadores extraños, ya sea por compañerismo o por sentimiento de paisanaje, que dejarían de subsistir si se dictara un ley sobre el problema que nos ocupa hoy. 
Si bien en las salitreras los indígenas fueron generalmente obreros, no por ello los oficios que desempeñaron fueron irrelevantes, por ejemplo, los mejores cateadores de caliche, arrieros, cortadores de yodo, propios y particulares fueron indígenas; de hecho, éstos eran muy requeridos por los administradores. Su inestabilidad laboral fue más bien producto de migraciones estacionales (agrícolas) a sus comunidades.

El conocimiento minero que tenían algunos indígenas locales venía de la explotación de la plata y cobre en minas como Huantajaya, Santa Rosa y Collahuasi, los que venían de Bolivia, traían conocimientos de las minas de Potosí y Oruro. Debido al sistema de extracción a rajo abierto, llamado calicheras, esos conocimientos les fueron más útiles en los lugares donde se extrajo el caliche a través de cuevas (v. gr. Santa Rosa de Huara).

Los indígenas no solamente se incorporaron a las salitreras en tanto trabajadores, sino además establecieron relaciones de intercambio comercial entre éstas y sus pueblos o comunidades de origen; fue el caso de indígenas de los valles y altiplano chilenos (aymaras) como indígenas de los valles y altiplano boliviano (quechuas y aymaras), generando ello un complejo proceso económico de mutua dependencia e influencia, en el cual se intercambiaban básicamente productos agropecuarios (v. gr. alfalfa, vinos, chicha, frutas, carnes, charqui, lana, tejidos, harinas, etc.) por productos elaborados (calaminas o zinc, planchas y cocinas de fierro, alimentos envasados, etc.).

Por último, a pesar de la aparente instrumentalización de los indígenas del enclave salitrero, éste salarizó y proletarizó a esa mano de obra. La incorporó laboralmente a un tipo de explotación industrial que para la época fue moderna. La socializó en un tipo de organización obrera internacionalista. Compartió una sociabilidad en los campamentos salitreros basada en un tipo de comunidad urbana esencialmente solidaria y contradictoria, que transformó al indígena en ciudadano. Debido al obligado retorno a sus lugares de origen después de la gran crisis de los años treinta, todo ello debió tener un impacto cultural en las comunidades campesinas de valles (chilenos y bolivianos) y altoandinas (chilenas y bolivianas) que no ha sido estudiado aún.

\section{La Tirana, Festividad Salitrera}

En la fiesta de La Tirana (16 de julio), incluso en su versión urbana en Iquique (28 de julio), La Tirana grande y La Tirana chica, respectivamente, es notoria la presencia indígena en las cofradías y en las bandas de músicos. Sin embargo, no es una identidad que se exprese en el escenario de la festividad como tal, sino que se entremezcla con el carácter mestizo del fenómeno, porque la fiesta de La Tirana es una festividad mestiza, como lo fue la sociedad del nitrato.

En 1987 entrevistamos a la directiva de la Sociedad Internacional de Artesanos de Iquique. Había cinco personajes vestidos de rigurosos ternos oscuros, formales, amables, rodeados de símbolos mutualistas, además de ocupar una sala del hermoso edificio de la Sociedad ubicado en la esquina de Zegers con Barros Arana, frente a la escuela Santa María. A comienzos de siglo XX la Sociedad Internacional de Artesanos tenía también en su segundo piso una escuela para obreros y obreras, bajo la inspiración de Fermín Vivaceta. Entre esos solemnes caballeros había uno que nos era especialmente familiar, mientras avanzaba la entrevista reconocimos en ese rostro al "brujo" de los pieles rojas del barrio El Morro, una cofradía de La Tirana de origen salitrero. No fue tarea fácil reconocerlo, pues el "brujo" usaba un gorro de piel con cachos parecidos a los de un bisonte, con una piel a modo de capa, un pequeño tambor de cuero en su mano izquierda que golpeaba mientras saltaba entremedio de los bailarines, muy diferente al formal personaje de terno gris de la directiva de la Sociedad Mutualista ${ }^{4}$.

Por cierto, tiempo después lo entrevistamos en su casa para que nos explicara esa dualidad tan -aparentemente- contradictoria. Como casi todas las cofradías antiguas de La Tirana, la de "los pieles rojas" de Damián Mercado había llegado de la pampa salitrera después de la gran crisis de los años treinta. Los "pieles rojas" como otras cofradías fueron inspirados de los biógrafos que se construyeron en los campamentos salitreros.

Ese mismo año entrevistamos a la señora Cristina Guzmán, boliviana de Oruro, ella llegó con sus padres al cantón de Negreiros, que se caracterizó por recibir a los enganches venidos de Bolivia. Ella vivió en la gran salitrera Agua Santa y en Tres Marías. Tuvo la amabilidad de obsequiarnos una fotografía de comienzos de siglo donde está 
ella vestida de angelito, con unos once años de edad, en medio de una cofradía de bolivianos, donde había reyes magos, diablos, sueltos, hadas, etc. (Figura 4). Esta cofradía, como otras, fueron organizadas en las salitreras mucho antes que el baile chino, fundado en 1905, que hoy tiene el derecho de sacar a la Virgen en La Tirana por ser "el más antiguo". En realidad el baile chino es el más antiguo de los bailes chilenos de La Tirana; en cierta forma, las cofradías antiguas de origen peruano o boliviano, como todas las instituciones tarapaqueñas, sufrieron el compulsivo proceso de chilenización a partir de 1911 (González et al. 1994).

Proponemos las siguientes conjeturas respecto de La Tirana:

(1) Que es una festividad andina. Asociada a la tierra, a la fertilidad, a la salud, a la pachamama (van Kessel 1989), al ciclo agrícola, vinculada a la virgen de Copacabana. Esta característica apela a la dimensión campesina oculta del obrero salitrero.

(2) Que es una festividad salitrera. Si bien sus orígenes mineros que hunden raíces en Huantajaya han sido comprobados (Núñez 1988), pero el hecho mismo que la memoria no los recuerde con claridad indica un quiebre histórico en esta fiesta de gran importancia social y cultural. En el siglo diecinueve esta fiesta fue re-fundada y vivió una expansión junto al desarrollo del ciclo del salitre. Ningún baile guarda algún vestigio o signo del pasado argentífero.

(3) Fue una festividad autónoma y popular. Hasta 1917 estuvo divorciada de la autoridad eclesiástica. De su anticlericalismo, aún quedan resabios hasta nuestros días. La labor impositiva de Monseñor José María Caro primero, y la labor integradora de los curas oblatos y diocesanos, después, algunos de los cuales se hicieron promeseros, ha permitido el acercamiento de los bailes al rito católico formal y a la autoridad eclesiástica.

(4) Esta fiesta sufrió el impacto de la chilenización en Tarapacá. Siendo el primer indicador la fecha de la celebración (eliminación del 6 de agosto, para dejar exclusivamente el 16 de julio) y el simbolismo nacionalista que comenzó a recibir la "chinita", transformada en Patrona de la Patria y del Ejército de Chile.

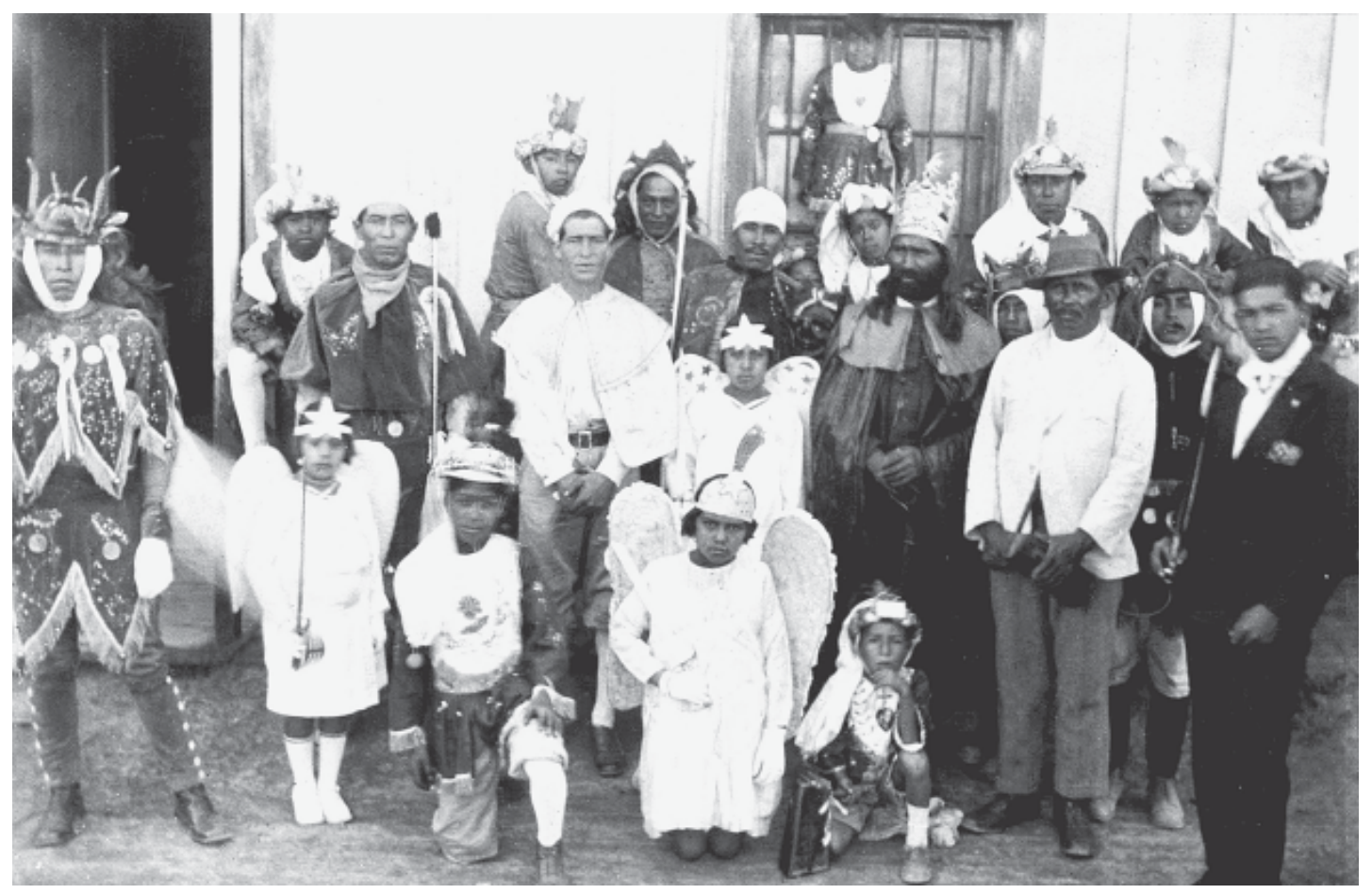

Figura 4. Cofradía boliviana en salitrera del cantón norte de Tarapacá, año aproximado 1905.

Bolivian religious parade party in the nitrate mine o Tarapaca's north canton, approximately 1905. 
El primer punto no será tratado aquí porque los trabajos de J.J. van Kessel y L. Núñez lo dejan meridianamente comprobado en sus interesantes investigaciones.

En segundo término, durante el ciclo del salitre el indígena-obrero se sumergió en medio de una sociedad intercultural, el censo peruano de 1878 registra treinta y seis nacionalidades distintas en la provincia y el de 1907 treinta y tres. Tarapacá era plurinacional y pluriétnica. Los indígenas estaban menos en los clubes sociales, filarmónicas y en las sociedades mutualistas, pero más en las cofradías y estudiantinas. Podían estar en los sindicatos pero escasamente en los partidos políticos. Su huella es difícil de rastrear en los periódicos y archivos, pero está en la memoria colectiva del tarapaqueño. Se invisibilizaba en la huelga, pero emergía en la festividad. Y en La Tirana surgía con todo su colorido y simbolismo. Simbolismo que la autoridad eclesiástica y los grupos ilustrados nunca entendieron durante el ciclo de expansión del salitre, como puede observarse por las notas de prensa.

La iglesia de La Tirana es salitrera en su construcción, de calamina y pino oregón. Dos hechos no deseados colaboraron para que se levantara un nuevo templo en La Tirana: si el terremoto de 1868 no la destruyó completamente, el de 1877 debió concluir la faena. La actual es de 1886, es decir, en pleno repunte salitrero, había entonces dinero para invertir en un templo, que se construyó por erogaciones de los fieles. Según Silva Lezaeta:

El edificio es muy nuevo, el material fino en el interior y de fierro galvanizado en el exterior aunque el constructor carecía de conocimiento de arquitectura pues domina en el templo el mal gusto de las construcciones españolas del tiempo de la decadencia del arte en la Madre Patria, el conjunto del edificio produce agradable efecto por estar perfectamente terminado y pintado (citado en: Núñez 1988:43).

Decir que la fiesta de La Tirana es salitrera no significa negar lo andino, lo indígena, lo campesino, a pesar de ser la sociedad del salitre plenamente minera y moderna. La dualidad del "caporal" que era mutualista fue un rasgo de esta sociedad compleja. El pampino poseía ríos subterráneos de identidad, los promeseros, romeros, bailarines, figurines, caporales, etc., eran mayoritariamente obreros pampinos. Quizás lo más directamente andino fueron (y siguen siendo) los integrantes de las bandas que acompañaban a las cofradías. Así como en nuestros días los bailes ensayan todo el año en la ciudad (sea Iquique, Tocopilla, Arica o Calama), en esa época lo hacían en los campamentos salitreros. Es decir, formaban parte de la cotidianidad de la salitrera. El sonido de las bandas era tan común como el silbido del viento. A continuación una inserción en semanario católico La Luz, donde se confirma lo anterior:

\section{La Fiesta del Carmen en Negreiros}

Grandiosas han sido las demostraciones de intensa devoción a la excelsa Patrona de las Armas Chilenas celebradas en Negreiros el domingo pasado.

No obstante de estar paralizados los trabajos en la mayoría de las oficinas salitreras, acudió un gentío inmenso.

El acto principal fue la procesión que se efectuó en la tarde. La imagen de la Virgen del Carmen primorosamente arreglada en un camión facilitado por D. Tomás O'Conner, administrador de la oficina "Aurora", fue llevada en triunfos por las calles de la población cuyos edificios estaban engalanados con banderas nacionales. El vehículo convertido en anda y trono de la Virgen Carmelitana, ostentaba trofeos bélicos, banderas tricolores y hermosas flores que hacían un conjunto imponente y hermoso (...) La Luz $\mathrm{N}^{\circ} 673$ Iquique, 12 de julio de 1925.

La fiesta de La Tirana era en los campamentos salitreros una actividad de meses, que implicaba organización y relaciones complejas al interior de los campamentos. Y si consideramos que la Iglesia participaba sólo marginalmente en esa época, toda la responsabilidad era de los caporales que en cierta forma fueron tan relevantes para la sociedad salitrera como lo fueron los presidentes del sindicato o de la filarmónica.

Acorde a lo propuesto en el tercer punto, esta última afirmación relativa a una autonomía de los bailes de promeseros de la autoridad eclesiástica, que sostenemos es coherente con la influencia anticlerical salitrera, puede comprobarse con las propias palabras del más importante Vicario y Obispo de Tarapacá, Monseñor José María Caro (1969:66): 
En la parte de la pampa llamada la Tirana, no lejos de Pozo Almonte, hay un templo grandecito, en honor a nuestra señora del Carmen, en el cual se venera una imagen. Se celebra su fiesta. Con grandes concursos de gente, que acude de todas partes, con mucha música, tamboreos y explosiones de "camaretas".

Aquí aprovecho esta ocasión, para manifestar la observación que hice, durante mi permanencia en Iquique, acerca de la devoción a Nuestra Señora del Carmen. Se mantiene sola, sin que tenga promotores de esa devoción, como sucedía con otros títulos y devociones, para honrar a nuestra señora: los Franciscanos promovían la devoción a la Purísima, los Salesianos a la María Auxiliadora, los Mercedarios a Nuestra Señora de la Merced, los Redentoristas a Nuestra Señora del Perpetuo Socorro. Nuestra Señora del Carmen, como he dicho, era honrada espontáneamente por el pueblo, que a pesar de su propia irreligiosidad, cuando se trataba de una procesión a la Virgen del Carmen, como lo vi también en otra parte, y lo mismo en La Tirana, tomaba parte en la procesión con todo entusiasmo. No dejaba de llamar la atención, el homenaje que, sobre todo, las mujeres de la provincia, solían ofrecerle a la Santísima Virgen, llevando velas que encendían ante su imagen, y se sentaban en el pavimento, a observar la vela hasta que se consumía, renovándola a veces, según la manda.

Efectivamente, hemos podido descubrir que en la fiesta de 1917 monseñor Caro ordenó la forma de ocupar el templo, pero además los rotuló bajo el ritual católico formal, basado en santos patronos y no por lugares de origen (oficinas salitreras). Creemos que fue el primer paso de cooptar a las cofradías por parte de la Iglesia. Monseñor Caro ${ }^{5}$ viajó desde Iquique al Alto San Antonio, primero, para después ir a La Tirana por un par de días a dar la comunión a los promeseros o romeros. Según un artículo publicado en La Luz № 247, del 22 de julio de 1917, titulado: Los Bailes de la Tirana, se señala lo siguiente:
Los caporales de los bailes se reunieron delante del Sr. Obispo y tomaron los siguientes acuerdos:

$1^{\circ}$ Guardar entre sí este orden y los nombres que se indican en lugar de los antiguos, que van entreparentesis:

$\mathrm{N}^{\circ} 1$ Chinos y Danzantes (Cala Cala) del Carmen.

$\mathrm{N}^{\circ} 2$ Chunchos de (Cala Cala) San Gerardo.

$\mathrm{N}^{\circ} 3$ Morenos (de Negreiros) del Rosario.

$\mathrm{N}^{\circ} 4$ Morenos de (Cala Cala) San Juan. $N^{\circ} 5$ Cullaves (de la Aguada) del señor de Sipiza.

$\mathrm{N}^{\circ} 6$ Cullaves de (B. Retiro) San Isidro. $\mathrm{N}^{\circ} 7$ Lacas de (Negreiros) San Guillermo.

No 8 Callahuayes de (Pan de Azúcar)

San Antonio.

N 9 Chunchos de (Cala Cala) San José. $\mathrm{N}^{\circ} 10$ Cullaves de (Galicia) la Candelaria.

Los bailes nuevos seguirán su enumeración.

$2^{\circ}$ Nadie debe entrar a la Iglesia con caretas, máscaras, figurines, etc.

$3^{\circ}$ Cuando está cantando un baile en la Iglesia, el que va entrando no debe interrumpirlo.

$4^{\circ} \mathrm{El}$ caporal de cada baile debe llevar visible su número.

$5^{\circ} \mathrm{El}$ caporal del número 1 hace de Director general, para el caso que fuera necesario.

En esta reunión se hizo un recuerdo cariñoso del caporal M.A. Moreira.

P.S. Se hizo el cambio de nombres, tanto para dar un patrono a cada baile, como para distinguir más fácilmente los que antes tenían el nombre de una misma Oficina y para evitar que se llamara con un nombre que no correspondiera ni al caporal que lo organiza ni a los miembros que lo componen.

El conflicto entre los caporales, autoridad de las cofradías, y los curas urbanos y obispos, la autoridad eclesiástica, expresa un campo de fuerza, donde el poder institucional estaba con los segundos; muy fuerte en la costa urbana pero que en la 
pampa salitrera se diluía. La evangelización en las salitreras recayó en las manos de los franciscanos y de algunos curas diocesanos que ejercían su labor en pueblos de los valles interiores ${ }^{6}$. Los dueños de salitreras no construyeron parroquias en los campamentos ${ }^{7}$. Hasta 1910 muchos de esos curas eran extranjeros, incluso de nacionalidad peruana. La chilenización le permitió a la Iglesia reemplazarlos por capellanes y aumentar lentamente su influencia en los pueblos de valles primero y del desierto después, donde La Tirana no estuvo ajena.

Respecto del cuarto punto, el proceso de chilenización iniciado en Tarapacá en forma compulsiva después del centenario de la República, penetró a todo el tejido social, incluyendo a una festividad aparentemente ajena como La Tirana. Antes de este proceso, en Tarapacá, se sabe que La Tirana era una festividad que se celebraba en fechas diversas, a saber: el 6 de agosto (fiesta de los bolivianos) y el 16 de julio (fiesta de los chilenos). Sabemos que el 28 de julio (fiesta de los peruanos) fue una fecha escogida en algunos años.

Por ejemplo, el diario El Tarapacá del domingo 4 de agosto de 1895, bajo el título de La Tirana, señala:

Hoy tiene lugar en el pueblecito de ese nombre, situado, como se sabe, a corta distancia de Pozo Almonte, la grande y proverbial fiesta anual que se celebra aquel devoto vecindario en honor a la Reina de los cielos.

Acuden a ella en colosal y alegre romería, gente de todos los puntos de la provincia, como sucede en Coquimbo cuando se celebra la legendaria fiesta de la virgen de Andacollo.

Con motivo de esta festividad La Tirana se anima y se regocija como cualquier profano en el día de su boda, entregándose con frenesí entre lo divino y lo humano a los placeres que dan la buena música, los bailes y los buenos tragos sobre todo.

En cuanto a los resultados de la devota práctica, son verdaderamente milagrosos y se obtienen infaliblemente a los nueve meses...

Nos parece necesario unir este párrafo a otro escrito ocho años después por el corresponsal en la pampa del diario El Nacional, cuyo seudónimo era Pepe Hillo:

Viernes 24 de julio de 1903

Las diversas cuadrillas de danzantes que se dirigieron a solemnizar las fiestas del Carmen de La Tirana, regresaron anteayer de Pozo Almonte, en un convoy de 19 carros. Los recién llegados dicen que la concurrencia que asistió a la fiesta lo pasó agradablemente, pues, aparte de las ceremonias religiosas que ofició el ilustrísimo señor Obispo, los devotos y los profanos han pasado verdaderos días de campo gozando a sus anchas.

Verdad que la afluencia de gente no fue como en años anteriores, debido quizá a la situación porque atraviesa la provincia, con la epidemia encima (bubónica) y otras calamidades; pero la fe de los creyentes no ha disminuido y la alcancía de la virgen, patrona de La Tirana, no ha quedado muy vacía esta vez.

Los preparativos para las próximas festividades del 28 de julio, siguen la pampa en su punto. En la oficina Rosario de Huara se prepara un gran baile para el que ya se han repartido más de 100 invitaciones. Iguales manifestaciones se preparan también en otras oficinas de los alrededores de Huara. Parece, pues, que el próximo 28 de julio será celebrado ruidosamente por peruanos y chilenos, en amable consorcio, que indudablemente contribuirá a borrar las asperezas del pasado, honrando esta fecha común a todo Latinoamérica...

Estos párrafos entregan cuatro claves importantes: (1) confirman las celebraciones en julioagosto, asociadas a las fiestas patrias de Perú y Bolivia y a la Virgen de Copacabana, (2) ya se puede observar que la convocatoria de La Tirana es amplia a nivel provincial y con la presencia del Obispo, indicando que su importancia ya era significativa para la autoridad eclesiástica ${ }^{8}$, (3) el uso de la música y los bailes, como su característica, demostrando que fueron siempre el principal rasgo de la fiesta. Los bailes a los que se hace mención son todos más "antiguos" que el "primer" baile de La Tirana: el Chino, (4) la referencia a los embarazos de las mujeres que, supuestamente, se en- 
tregarían a los placeres "humanos" durante la festividad. Esto último ha sido recurrente en periódicos de épocas posteriores, señalando algunos incluso que esos embarazos no son criticados, aunque las mujeres sean solteras o casadas. Cabría hacer un análisis respecto de la fertilidad de la pachamama y esos embarazos.

El proceso de chilenización de la fiesta llegó esencialmente a través de la propia Iglesia, que acentuó el carácter patriótico de la virgen, sus orígenes militares al comienzo de la República y su carácter de "patrona del ejército". De hecho, la autoridad eclesiástica iquiqueña siempre intentó darle más importancia a las festividades de la novena del mes de septiembre, llamándola "la fiesta grande" y celebrándola en la Iglesia Vicarial, posiblemente como una forma de disminuir la importancia del pueblo de La Tirana, por su supuesto paganismo. Por ejemplo, La Luz - $\mathrm{N}^{\circ} 37$ del 13 de julio de 1913 señala lo siguiente:

\section{La Tirana}

Llega la fiesta de la Tirana y con ella el tumulto de devotos, el incesante ruido de tambores e instrumentos músicos y la alegre animación de los romeros.

Es un paréntesis en la triste y monótona vida de la Pampa; es una tradición, ya formada, de muchos fieles y de muchas familias, difícil, por no decir imposible, de suprimir; es un desahogo que el corazón naturalmente cristiano y amante de la Virgen Madre de Dios busca su fe, oprimida por la indiferencia o por el respeto humano, en el teatro ordinario de la vida.

Esas manifestaciones de fe y de amor cada cual las practica con la buena intención y del mejor modo que se le ocurre; el canto, la música, las flores, las velas, los cohetes o voladores, las ofrendas de trajes, las mandas de misas, son la expresión más elocuente de sus sentimientos de piedad hacia la Virgen. Para otros la mejor ofrenda consiste en purificar su alma del pecado, en arreglar su matrimonio, si están viviendo mal, y ofrecer en honor a la Sma. Virgen una fervorosa comunión.

Estos últimos obsequios son sin duda los más agradables a la Sma. Virgen...

Y La Luz, Nº673 Iquique, 12 de julio de 1925.

\section{La Fiesta de La Virgen del Carmen} Se celebrará el jueves, día 16 de este mes es una festividad que no puede ser indiferente a ningún chileno que conozca la Historia nacional.

Son muchas las vinculaciones que existen entre la Virgen del Carmen y la República de Chile.

Los héroes de la independencia reconocieron la protección especial que les dispensó la Virgen Carmelitana, a la cual acudieron en los momentos trascendentales de la vida de la Patria. La reconocieron como Generala del Ejército y le juraron fidelidad: en testimonio de ello San Martín le entregó el bastón de mando.

Todos ellos se gloriaban de vestir el Escapulario del Carmen, como escudo protector de combates.

En la guerra del Pacífico todos los soldados, desde el General al corneta, todos los marinos desde el Almirante hasta el último grumete, llevaban la sagrada insignia. Las madres al entregar a sus hijos a la suerte de la guerra, los armaban con el Escapulario de la Virgen del Carmen.

Entre los restos del insigne Prat, se encontró el Escapulario de la Virgen del Carmen...

Sabemos que la chilenización fue particularmente severa y xenófoba con la población tarapaqueña de origen peruano o peruana residente ${ }^{9}$. Muchos debieron partir bajo la ignominia al Perú como refugiados, perdiendo sus bienes y separándose de su familia y amigos. El grueso de los refugiados tarapaqueños que llegaron al Callao-Perú fueron instalados en terrenos de un ex fundo llamado La Chalaca. Allí les entregaron sitios bajo el gobierno de Augusto B. Leguía, para que construyeran sus casas. Por el tamaño de esta población se transformó pronto en una urbanización denominada con acierto: Tarapacá.

Lo aparentemente irónico es que esta Virgen del Carmen, Patrona del Ejército de Chile, es precisamente la patrona de estos tarapaqueños, la que se ha transformado con el tiempo en una imagen de gran importancia en todo el Callao. Ellos tienen su propia leyenda y su propio templo, pero la Virgen del Carmen del Callao es una réplica exacta de la "chinita del Tamarugal". Los tarapaqueños re- 
cogieron de la Virgen del Carmen precisamente su carácter de "chinita", de pachamama y de la imagen sagrada de los "irreligiosos" y anticlericales pampinos.

Según el ex bailarín, antropólogo y sacerdote Pablo García Vásquez (comunicación personal), más allá de un cierto anticlericalismo, las cofradías de baile pueden ser consideradas como experiencias tempranas de asociatividad. La iglesia tarapaqueña descubre este tipo de organizaciones y se las apropia, asimilándolas (haciéndolas reconocibles nominalmente) pero no las institucionaliza, porque no sabe cómo hacerlo. El primer intento institucionalizador, señala García, vendrá en 1933, pero fue ésta una experiencia fallida y recién, en la década de los años sesenta, con el nacimiento de la Federación de Bailes de La Tirana, la institucionalización será completa. Donde se sustenta lo siguiente: (1) Toda organización eclesiástica contempla la presidencia honoraria del obispo o un clérigo. Antes de la Federación mencionada no existía tal presidencia. (2) Toda organización eclesiástica poseía un orden estatutario emanado y refrendado por la autoridad eclesiástica, cuestión que tampoco fue así antes de la Federación. Una de las tareas de Monseñor Caro fue la de pasar del esquema de la limosna, según el esquema del cooperativismo propuesto por León XIII en Rerum Novarum de 1891. De ahí la importancia del cura Vives y su presencia en Iquique y el caporal Moreira, a quien se le hace un homenaje en 1917, participó de la Semana Social del año anterior y fue uno de los oradores que cerraron dicha jornada.

\section{Palabras Finales}

Este artículo no ha tenido otra pretensión que demostrar tres aspectos de la fiesta de La Tirana, a saber:

(1) Su carácter salitrero, lo que tendría dos aspectos: uno, el minero, que le dio la identidad a las cofradías, y dos, el desierto, que le dio el misticismo.

(2) El origen espontáneo de este fenómeno cultural, es decir, independiente de instituciones eclesiásticas, que explica ese sincretismo entre la religiosidad popular y el anticlericalismo, tan propio de la expresión popular de la fiesta.

(3) El impacto del proceso de chilenización en esta festividad, que obligó al ocultamiento de sim- bologías compartidas por las tres nacionalidades del pueblo (chilena, peruana y boliviana) y con ellas la indígena. Además de la emergencia de la simbología militar y patriótica asociada a la Virgen del Carmen, Patrona del Ejército.

Si bien el inicio del ciclo de expansión del salitre pudo haber marcado definitivamente la ruptura con el origen argentífero de La Tirana, siendo la construcción del nuevo templo (1886) el símbolo de ese quiebre, es posible que el término del ciclo de expansión del salitre haya significado otra inflexión, donde en eje sociocultural de La Tirana se traslada del desierto a la costa. Y el símbolo de esa ruptura sea la creación del templo de la Plaza Arica para la Virgen del Carmen en Iquique, en 1933. Transformándose en la "Tirana Chica"10. Veamos el programa de ese año, cuando el obispo era monseñor Carlos Labbé, publicado en El Tarapacá, martes 10 de octubre 1933.

\section{En la Nueva Capilla de Nuestra Señora del} Carmen

Desde el domingo 8 se ha empezado una santa misión, a cargo del obispo, Monseñor Carlos Labbé M. en la nueva Capilla, dedicada a la Virgen del Carmen, habilitada en la calle San Martín esquina Plaza Arica.

Durante estos días habrá misa a las 8 a.m. con plática; en la tarde a las 4:30 catecismo para los niños del barrio. Se atenderán también gratuitamente, bautizos, matrimonios, etc.; en la noche a las 8:30 se efectuará la distribución principal de la misión, con plática y sermón. Todos estos oficios a cargo del Iltmo. señor Obispo.

En esta ocasión, en que entusiastas señoritas que componen la Asociación de la Juventud Católica Femenina, tiene un ancho campo en que desarrollar sus piadosas labores, trabajando tesoneramente para el mayor bien de estas misiones, secundando completamente al señor obispo, consiguiendo la mayor cantidad posible de bautismos, matrimonios y en la preparación de los niños para su primera comunión. De esta manera, el día 12, que es el día de la bendición oficial de la nueva Capilla, serán muchas las comuniones y demás servicios religiosos. 
Los bailes de "chunchos" organizados de la Capilla, han confeccionado un programa de fiestas más o menos igual, a los que se acostumbran desarrollar en la Tirana, en el día de Nuestra Señora del Carmen. El programa es el siguiente: El día 12: A las 8:30 bendición de la Capilla de la Virgen del Carmen, misa y comunión general.

A las 3:30 p.m. Solemne procesión con las andas de la Virgen y de Andacollo, Ángel de Chile y San Antonio, que se veneran en la nueva Capilla; asistirán los chunchos con sus trajes característicos; Al regresar a la Capilla el señor Obispo dará la bendición papal se bendecirán los objetos religiosos, como se acostumbran en las misiones.

Parte Social:

Día 11: A las 4 p.m. Presentación de los Bailes ante la nueva Capilla.

Día 12: A las 4 a.m. Alba cantada por las diversas comparsas de bailes tradicionales. A las 6 a.m. Diana por la banda músicos.
Según la antropóloga Hanneke Slootweg, las cofradías religiosas son todavía un fenómeno obrero, tal y como surge en las salitreras de Tarapacá $^{11}$. Esta fiesta reúne hoy a no menos de cien mil personas todos los años, más que toda la población indígena de la región, en un gran ritual intercultural, que no solamente sobrevive sino crece con los años, está presente y, como siempre, es un fenómeno que está más allá de la Iglesia oficial. La Federación de bailes religiosos cuenta con más de cuatro mil socios activos, más que cualquier federación obrera o patronal: la cofradía tuvo al cabo mejor salud que el sindicato. El gran ritual intercultural de La Tirana es todavía una expresión de identidad regional. Esta festividad, organizada por los "de abajo", construida por los "ocultos", se impuso en el largo plazo e hizo visibles sus "ríos subterráneos" en toda la región y más allá de sus fronteras.

Agradecimientos: FONDECYT 1020719 y a los revisores anónimos de Chungara.

\section{Referencias Citadas}

Cámara de Diputados

1913 Comisión Parlamentaria Encargada de Estudiar las Necesidades de las Provincias de Tarapacá y Antofagasta. Talleres Zigzag, Santiago.

Caro, J. M.

1969 El Cardenal Caro (Autobiografía). Talleres Francisco Carrión e Hijos, Santiago.

Fernández Canque, M.

1988 Proletario y Salitre en Chile, 1890-1910. Monografía Nuestra Historia, Londres.

Foucault, M. 1994 Vigilar y Castigar. Editorial Siglo XXI, Madrid.

González Miranda, S.

2002 Hombres y Mujeres de la Pampa. Tarapacá en el Ciclo de Expansión del Salitre, 2da Edición. Lom, Unap, Dibam, Santiago.

1996 Quechuas y aymaras en las salitreras de Tarapacá. En Integración Sur Andina Cinco Siglos Después, editado por X. Albó, M.I. Arratia, J. Hidalgo, L. Núñez, A. Llagostera, M.I. Remy y B. Revesz, pp. 336-353. B. de las Casas, TEA, UCN, Cusco.

González, S., M.A. Illanes y L. Moulian

1998 Poemario Popular de Tarapacá 1899-1910. Dibam, Lom, Unap, Santiago.

González, S., C. Maldonado y S. Mac Gee

1994 Ligas Patrióticas. Un caso de nacionalismo, xenofobia y lucha social en Chile. Canadian Review of Studies in Nationalism 21:44-56.
Ginzburg, C.

1999 Mitos, Emblemas, Indicios. Morfología e Historia. Gedisa, Barcelona.

Goodson, I. e I. Dowbiggin

1994 Cuerpos dóciles. En Foucault y la Educación, compilado por Ball, S.J., pp. 107-132. Editorial Morata, Madrid.

Gundermann, $\mathrm{H}$.

1998 Comunidad aymara, identidades colectivas y estados nacionales. En A 90 años de los Sucesos de la Escuela Santa María de Iquique, editado por P. Artaza, R. Sagrado y S. González, pp. 153-182. Dibam, Lom, Unap, Santiago.

Hernández, R.

1930 El Salitre (Resumen Histórico Desde su Descubrimiento y Explotación). Fisher Hnos., Valparaíso.

Le Goff, J.

2002 Lo Maravilloso y lo Cotidiano en el Occidente Medieval. Gedisa, Barcelona.

Núñez A., L.

1988 La Tirana. Universidad del Norte, Antofagasta.

Palacios Rodríguez, R.

1974 La Chilenización de Tacna y Arica. 1883-1929. Colección Perú Historia. Editorial Arica, Lima.

Pereda, R.

1982 Historia de las Luchas Sociales del Movimiento Obrero en el Perú Republicano. 1858-1917. EDIMSSA, Lima.

Pinto V., J. y V. Valdivia O.

1984 Peones chilenos en tierras bolivianas: la presencia laboral chilena. Antofagasta. 1840-1879. Población y Sociedad 2:103-132. 
Pinto V., J.

1995 Rebeldes Pampinos: Patrones de Violencia Social en las Oficinas Salitreras (1870-1900). Usach, Santiago.

Reyes Navarro, E.

1973 El Desarrollo de la Conciencia Proletaria en Chile

(El Ciclo Salitrero). Editorial Orbe, Universidad del Norte, Santiago.

Rodríguez, G.

1991 El Socavón y el Sindicato. Ensayos Históricos sobre los Trabajadores Mineros, Siglos XIX y XX. ILDIS, Cochabamba.
Troncoso de La Fuente, R.

1986 La Migración de los Tarapaqueños Peruanos a Lima: 1907-1920. Tesis para optar al grado de Magister en Historia, Pontificia Universidad Católica del Perú, Lima.

van Kessel, J.J

1987 El Desierto Canta a María. Ediciones Mundo, Santiago.

s/a Lucero del Desierto Tomo II. Ciren, Iquique.

1989 El Santuario Andino como Dispensatorio de Salud y Vida. Centro de Medicina Andina, Cusco.

\section{Fuentes}

Diario El Pueblo de Iquique.

Diario El Tarapacá de Iquique.

Diario El Nacional de Iquique.
Semanario La Luz, Obispado de Iquique.

El Diario de Oruro.

Notas

1 El cuerpo es relevante en La Tirana porque en él se expresa el sacrificio que se ofrece a la virgen, sea a través del baile o de las mandas, entre otras manifestaciones; tomando en consideración, además, que este espacio es un dispensatorio de salud, donde el cuerpo se sacrifica para redimir o sanar el alma. Desde un punto de vista teórico, considero que el aporte de Michel Foucault sobre el disciplinamiento del cuerpo es interesante de aplicar a un fenómeno religioso como La Tirana (Foucault 1994; Goodson 1994).

2 Posiblemente la canción "Vamos mujer" dentro de la "Cantata Santa María” de Luis Advis V. exprese con más claridad esta distinción.

3 En los Memoriales Obreros de 1904 señala en una de sus partes: “...Últimamente, estando aún repleta de brazos la provincia, internaron al país miles de hombres traídos de la serranía de Bolivia y el Perú, porque la gente de pueblo no ha podido ser engañada. Esto se hizo con el fin expreso de irritar al obrero chileno de las provincias del Norte, a quien necesariamente debía afectar y herir, produciéndose así la anarquía y el choque consiguiente entre chilenos, peruanos y bolivianos, llevándonos a una segunda conflagración política de la cual sacaría el industrial provechosos resultados (...)". Manifiesto de los gremios obreros de la provincia de Tarapacá al Supremo Gobierno.

4 Lo pudimos divisar en La Tirana del 2001 ya no como brujo sino como cacique de otro baile Piel Roja, debido a su avanzada edad no dirigía, solamente su presencia era lo importante para el baile.

5 Posiblemente sea preciso señalar que Monseñor Caro llevó una activa disputa filosófico-política en Iquique con la masonería, por un lado, y con el comunismo por otro. Un famoso litigio en contra del periódico El Bonete dirigido por Elías Lafertte concluyó con éste y Luis E. Recabarren (director de El Despertar de los Trabajadores) en la cárcel. No es de extrañar entonces su preocupación por limitar a las cofradías salitreras.

$6 \quad$ La Luz N ${ }^{\circ} 717,11$ de julio de 1926. Fiesta de La Tirana. El próximo viernes 16 se celebrará la fiesta de La Tirana, como en años anteriores. Los peregrinos serán atendidos por el señor cura de Pica y por dos RRPP Franciscanos (el cura de Pica era el "tata" Friedrich, sacerdote alemán muy querido en la zona).

7 Después de la crisis de los años treinta, con la Cosach y bajo el apoyo económico de D. Osvaldo de Castro, se construyeron iglesias en importantes salitreras como Humberstone y Victoria. Además se trajeron curas oblatos y se difundió la Acción Católica organizada por el padre Hurtado, todo con el propósito de contrarrestar al comunismo.

8 Aunque ésta tratara de darle más importancia a otras festividades: en julio a la fiesta de San Pedro y San Pablo, y en septiembre a la novena por la virgen del Carmen, Patrona del Ejército.

9 Los trabajadores bolivianos no quedaron exentos de este problema, pues debieron sus brazos reemplazar a los de los trabajadores peruanos expulsados punitivamente por las autoridades o grupos organizados chilenos. V. gr. El Diario - Oruro, 1920. 24 de marzo, Notas de Uyuni. Enganches de trabajadores bolivianos para las salitreras. Es objeto de contradictorios comentarios la actitud de las autoridades de Uyuni, que han dado toda clase de facilidades a la comisión de reenganche de trabajadores que ha venido de Antofagasta. El sábado 13, se han embarcado en la estación de Uyuni, y con destino a la oficina salitrera "La Unión", 150 hombres de nacionalidad boliviana. Se asegura con muchos visos de verdad, que vienen en camino otras comisiones de reenganches, y que el propósito firme de los dueños, es reemplazar a todos los peruanos que permanezcan aún en ella, con elementos bolivianos.

10 El concepto de "Tirana chica" se refiere a la fiesta de la plaza Arica que es una réplica en menor escala de la realizada en el pueblo de La Tirana.

11 Posiblemente el cambio social y cultural mayor bajo esta nueva etapa de la fiesta de La Tirana, es que ya no es la expresión oculta de una cultura obrera emancipatoria, sino de otra cultura obrera: marcada por el consumo y el modernismo. 
